\section{Pós-graduação e trabalho: um estudo sobre projetos e expectativas de doutorandos brasileiros}

\section{Graduate studies and work: a study on the plans and expectations of Brazilian doctoral candidates}

\section{Rita de Cássia Ramos Louzada}

Professora do Departamento de Psicologia Social e do Desenvolvimento da Universidade Federal

do Espírito Santo - UFES

Av. Venceslau Brás, $71 \mathrm{fds}$

22295-900 Rio de Janeiro - RJ Brasil ritacrl@uol.com.br

\section{João Ferreira da Silva Filho}

Professor do Departamento de Psiquiatria e Medicina Legal da Faculdade de Medicina da

Universidade Federal do Rio de Janeiro Av. Venceslau Brás, $71 \mathrm{fds}$

22295-900 Rio de Janeiro - RJ Brasil

jferreira@ccsdecania.ufrj.br
LOUZADA, R. de C. R.; FILHO, J. F. da S.: Pós-graduação e trabalho: um estudo sobre projetos e expectativas de doutorandos brasileiros.

História, Ciências, Saúde - Manguinhos, v. 12, n. 2, p. 265-82, maio-ago. 2005.

O presente estudo analisa a relação entre a pós-graduação e o trabalho através de observação participante e relatos de um grupo de doutorandos, de um curso de excelência, na área de ciências da saúde (básica). As entrevistas ( $\mathrm{n}=12)$, individuais e realizadas nos moldes do método de história de vida, foram gravadas, integralmente transcritas e submetidas à análise de conteúdo. Os resultados mostraram que a maioria dos doutorandos apresentava dúvidas quanto à futura inserção laboral e tinha interesse em trabalhar na universidade pública. Além disso, e em função do número insuficiente de postos permanentes de trabalho em ciência no país, os entrevistados pensavam em alternativas que envolviam, por um lado, as instituições de fomento, através de bolsas (pós-doutorado, projetos de pesquisa em colaboração), e por outro, os contratos temporários de trabalho (professor visitante em instituições públicas). Esses resultados são discutidos em função das metamorfoses observadas no campo científico.

PALAVRAS-CHAVE: pós-graduação; história de vida; trabalho; formação; ciência.

LOUZADA, R. de C. R.; FILHO, J. F. da S.: Graduate studies and work: a study on the plans and expectations of Brazilian doctoral candidates.

História, Ciências, Saúde - Manguinhos, v. 12, n. 2, p. 265-82, May-Aug. 2005.

This analysis of the relation between graduate studies and work is based on participative observation and on the accounts of a group of doctoral candidates at a top school in the area of health sciences. Conducted using life history methodology, individual interviews $(n=12)$ were recorded, transcribed in full, and subjected to content analysis. Findings showed that most of these doctoral candidates had doubts about their future on the market and were interested in working at a public university. Furthermore, because there are not enough permanent job positions in science in Brazil, the interviewees were considering job alternatives that involved either research institutions (doing post-doctoral work or collaborative research under fellowships) or temporary contracts (visiting professor at a public institution). The article discusses the relationship between these findings and changes observed in the field of science.

KEYWORDS: graduate studies; life history; work; education; science. 


\section{Introdução}

$\mathrm{O}$ trabalho científico é um processo social que vem sofrendo mudanças significativas nos últimos anos; por extensão, podese dizer o mesmo com relação à formação de pesquisadores. Várias pesquisas, envolvendo tanto os estudos pós-graduados como a construção das carreiras em ciências, no âmbito internacional, trazem dados que sustentam esta afirmação.

Dados do final da década de 1990 mostram que os pósgraduandos têm começado seus cursos com idade mais elevada e levam um tempo maior para obter seus títulos. ${ }^{1}$ Além disso, observa-se que a taxa de doutores envolvidos em atividades fora de sua área começa, na atualidade, a chamar atenção. ${ }^{2}$ Ressalte-se, também, a atual discussão a respeito da experiência e do papel do pósdoutorando no mundo da ciência. ${ }^{3}$ E, embora não sejam numerosos, já é possível encontrar estudos qualitativos sobre 'pesquisadores contratados' e suas vivências laborais, ${ }^{4}$ tendo em vista a dificuldade de alcançar determinadas informações através de surveys. Todos esses estudos, encontrados na literatura internacional, dão conta do aumento da complexidade no trabalho científico e apontam, como peça-chave para o avanço da ciência, o pesquisador em formação (pós-graduando, postdoc).

Diante desses dados, esta pesquisa procura identificar as expectativas e projetos de doutorandos brasileiros quanto à carreira em ciências. Estamos, portanto, num cenário muito específico, que deve ser detalhado. Primeiramente, vale ressaltar que, em consonância com tendências internacionais (Slaughter \& Leslie, 1997; Easthope \& Easthope, 2000), observa-se que as diretrizes da universidade brasileira - onde a maior parte da pesquisa nacional vem sendo realizada - têm-se modificado. Um marco importante foi a edição da Lei de Diretrizes e Bases, em 1996, que demarca, por exemplo, categorias diferenciadas de instituições de ensino superior. Em segundo lugar, acompanha-se um crescimento intenso da pós-graduação brasileira nos últimos anos. $\mathrm{O}$ mesmo pode ser dito a respeito do número de alunos nesse nível de formação: em 1994 eram 43 mil pós-graduandos e em 1999 esse número chegava a 54 mil. ${ }^{5} \mathrm{Em}$ terceiro lugar, no âmbito da ciência brasileira, observou-se um significativo incremento da produtividade: 160\% entre os anos de 1995 e 1998. Mas, nesse mesmo período, e paradoxalmente, acompanhouse um decréscimo do orçamento disponível para custeio da ciência e tecnologia ( $C \& \mathrm{~T}$ ) no sistema federal, especialmente a partir de 1990, de acordo com Carlos Henrique B. Cruz (Scheinberg, 2000). Em quarto lugar, registre-se que o fomento à pesquisa no país esteve praticamente estagnado de 1998 a 2000, quando o governo federal acenou com um conjunto de medidas que instituíam um novo sistema nacional de fomento à pesquisa, com recursos dos 'fundos 
setoriais'. ${ }^{6}$ E por último, deve ser destacada a Lei de Inovação Tecnológica, cujo texto-base tem sofrido inúmeras alterações, em vista da complexidade do tema, e continua em tramitação no parlamento. De toda maneira, esse é um projeto de lei que tem sido apontado como uma peça-chave para o desenvolvimento do país, articulando as instituições de pesquisa e as atividades empresariais.

Levando em consideração esse cenário, perguntamo-nos: como se posicionam os futuros cientistas no que se refere à carreira? Onde e como pretendem trabalhar? Que tipo de impacto essas mudanças, observadas tanto na universidade brasileira quanto nas instituições de fomento à pesquisa, produziriam no modo de conduzir e planejar a carreira em ciências?

\section{Formação de pesquisador no Brasil ${ }^{7}$}

A maior parte da literatura nacional sobre a formação de pesquisadores aparece como subtema de outros maiores como: a formação da comunidade científica (Schwartzman, 1979), a profissão acadêmica (Balbachevsky, 2000), a produtividade científica (Leta, Lannes \& De Meis, 1998), o perfil da ciência (Leta \& De Meis, 1996). Ainda não são numerosos, no Brasil, estudos que abordem, em detalhe, o processo de formação de pesquisadores, com as especificidades de cada área de conhecimento e que considerem a formação em suas relações com as regras e o movimento do campo científico.

Especificamente sobre a formação científica destacamos os seguintes trabalhos na literatura nacional: Peixoto (1994), Leta (1999) e Carmo (2001).

Peixoto (1994) comparou a formação de pesquisadores em duas áreas distintas (humanas/sociais e exatas/natureza), mostrandonos diversos aspectos da relação entre Estado, ciência e tecnologia, bem como a feição elitista da concepção de ciência embutida nos Planos Nacionais de Pós-graduação (PNPGs) e os vários formatos assumidos pelos cursos de mestrado e doutorado nos programas de pós-graduação, nível A, no Rio de Janeiro. A autora ressalta, em conclusão, o caráter plural do mundo da ciência, sublinhando a impossibilidade de referirmo-nos a uma única comunidade científica.

Leta (1999) abordou a formação de pessoal qualificado para as universidades e institutos de pesquisa. A autora procurou identificar o perfil da pós-graduação brasileira estabelecendo a correlação com o recente avanço da ciência brasileira. Seus resultados indicaram crescimento da concessão de bolsas de pós-graduação, o mesmo ocorrendo com o número de matrículas e de títulos obtidos. Há também uma comparação desses dados com os encontrados em outros países (EUA, Alemanha e Reino Unido), onde se formam 
muito mais doutores por ano. Centrando-se nos indicadores 'publicações' e 'citações', a autora identifica que a área de melhor desempenho foi a de ciências exatas e da Terra. Seus dados, enfim, apontam para o fato de que o crescimento da 'comunidade científica' brasileira foi fundamental na maior visibilidade conquistada pela ciência realizada em nosso país.

Numa abordagem diferenciada, Carmo (2001) realizou um estudo de caso num departamento de ciência básica (bioquímica) com o objetivo de "compreender como se dá o funcionamento da política científica vigente" no país, nesse ambiente específico, abordando a formação do cientista pautada pela idéia de produtividade. Seus achados revelaram um ambiente marcado por grande liberdade de pensamento, hierarquia flexível, valorização do questionamento e do desempenho em geral. Quanto aos sujeitos entrevistados, verificou que possuíam duas características comuns: "a aquisição de conhecimento e a vocação, manifesta no prazer com que desempenham suas atividades" (p. 92). Além disso, ressaltou em sua discussão que "o cientista é um ser em formação ... o título acadêmico apenas não é o que legitima uma pessoa como um verdadeiro cientista" (p. 94-5, grifos no original).

De maneira geral, a formação do pesquisador aparece, na literatura, como um processo ainda artesanal. Estabelece-se, via de regra, uma relação pessoal entre o pesquisador-orientador e o pesquisador em formação.

A nosso juízo, não é possível estudar a formação sem considerar que essa relação (orientador-orientando) se insere num contexto específico: o campo científico. Por isso lançaremos mão da produção de Pierre Bourdieu (1982, 1989, 1997, 2001) para embasar nossa análise do tema. A noção de campo é útil especialmente para caracterizar as lutas cotidianas verificadas nesse ambiente, nem sempre faladas, nem sempre visíveis, que vêm caracterizar a chamada 'competitividade' existente na ciência. Tanto a relação orientadororientando, quanto cada um desses elementos (pesquisadores estabelecidos e os futuros pesquisadores), estão submetidos a regras gerais do campo científico. A noção de campo científico vem designar esse espaço relativamente autônomo, dotado de suas leis próprias e, como todo campo, pleno de forças que lutam para conservar ou transformar o status quo. Dito de outra maneira: as lutas são inerentes ao campo científico e tal espaço não pode ser pensado sem que se considere a estrutura social em que se insere.

\section{Pós-graduação e trabalho}

Especificamente quanto ao binômio pós-graduação e trabalho, a descontinuidade de pesquisas tem sido a marca em nosso meio, ainda sem tradição de avaliações contínuas dessa relação e acom- 
panhamento da evolução da mão-de-obra em ciências. Essa descontinuidade pode ser aferida através do intervalo observado entre as pesquisas brasileiras mais amplas sobre o tema: Spagnolo e Gunther (1986) e Velloso (2002).

Spagnolo e Gunther (1986) colheram dados de mais de $12 \mathrm{mil}$ mestres e doutores brasileiros, de diversas áreas, que estavam em atividade no período de 1981-1984. Seus achados apontaram que os pós-graduandos, naquela época, iniciavam o curso em média aos trinta anos (mestres) e 35 anos (doutores). Além disso, viram que menos da metade dos mestres estavam inseridos em instituições de ensino superior no início do curso e que, depois do curso, esse número saltava para $70 \%$. No caso dos doutores, cerca de $60 \%$ tinham inserção no ensino superior quando do início do curso e, depois do curso, esse percentual subia para $75 \%$. Outra informação relevante é a de que $40 \%$ dos doutores em atividade no país naquele momento se haviam formado no exterior.

Essa realidade mudou bastante com o crescimento da pós-graduação brasileira e a introdução de outros fatores relativos ao fomento e diretrizes do ensino superior no país. A pesquisa coordenada por Velloso (2002) dá bem essa medida. Nos vários capítulos do livro vão se descortinando distintas realidades, conforme as áreas de conhecimento, considerando perfil de pós-graduandos, motivação, satisfação com o curso, trajetória na pesquisa e remunerações.

Especificamente quanto às trajetórias profissionais de pósgraduandos brasileiros, encontramos, no mesmo livro, um capítulo assinado por Bôas, Barbosa e Maggie (2002), cuja pesquisa cobre nove áreas de conhecimento: administração, engenharia elétrica, clínica médica, engenharia civil, agronomia, bioquímica, física, química e sociologia. As autoras oferecem dados sobre mestres e doutores que "atuavam na academia", "iriam para a academia" ou "não atuavam na academia". Seus achados apontaram que, em administração, engenharia elétrica e clínica médica, os titulados atuavam, na maioria, fora da academia e que, na física, a atuação era mais marcada na academia. A física era seguida por química, sociologia e bioquímica com mestres e doutores também mais inseridos na academia. Segundo as autoras "não é difícil criar hipóteses explicativas para essas diferenças associadas à configuração específica do mercado de trabalho de cada um dos grupos profissionais. Esses, no entanto, não são passíveis de análise com os dados dessa pesquisa" (p. 411).

O que no trabalho citado se anuncia como limite, em nosso caso figura como eixo: interessa-nos investigar as expectativas e os planos de carreira dos futuros doutores brasileiros diante das inúmeras mudanças no mundo do trabalho científico. Dito de outra maneira, pretendemos pensar a formação tomando como eixo o mundo do trabalho científico. 


\section{Método}

Trata-se de um estudo qualitativo com um grupo de doze doutorandos, matriculados em um programa de excelência na área da saúde, de uma universidade pública brasileira. O grupo continha sujeitos de ambos os sexos. Três sujeitos eram casados, um separado e todos os outros solteiros. A faixa etária ficava entre 25 e quarenta anos.

Foram utilizadas entrevistas em profundidade, conduzidas de modo próximo ao método biográfico. A escolha desse tipo de entrevista relacionou-se ao fato de esta proporcionar mais detalhes a respeito dos sujeitos e suas práticas, pautada por um relato mais livre, abrindo espaço para aspectos subjetivos, singulares. Mas não somente. Parte-se da idéia de que, ao narrar, os entrevistados apresentam seus valores, suas visões de mundo, além de informações relevantes do que é compartilhado e comum ao grupo pesquisado.

Além dos relatos, contamos também com informações resultantes da observação participante desse grupo, no período das atividades de campo (1999-2000), em suas atividades no departamento (cotidiano, seminários e cursos).

Os doutorandos foram contatados em seu local de formação e entrevistados individualmente, em função de sua disponibilidade para a pesquisa. As entrevistas foram gravadas, transcritas e submetidas à análise de conteúdo (Bardin, 1987). De todo o material colhido, priorizamos, para este trabalho, os temas e subtemas relativos ao futuro na atividade científica.

\section{Resultados e discussão}

Todos os entrevistados estavam, à época da pesquisa, formalmente inscritos no mesmo programa de pós-graduação em ciências da saúde (básica), numa universidade pública. Todos eram doutorandos, encontravam-se em diferentes momentos do curso e mantinham grande envolvimento na atividade de pesquisa, com carga horária alta nos laboratórios onde se inseriam, o que podia chegar a dez horas diárias por causa da pesquisa, podendo, até mesmo, incluir os fins de semana. Além disso, era comum o envolvimento desses estudantes em múltiplas atividades e projetos de pesquisa. De maneira geral, todos consideravam-se muito apoiados por seus chefes/orientadores, característica que, como veremos, não pode ser negligenciada em tal cenário.

Onze dos entrevistados apresentavam dúvidas em relação ao seu futuro na pesquisa. O contraponto disso era a certeza de que precisavam 'continuar trabalhando' para destacar-se no mundo da ciência, de 'extrema competitividade'. A fala deste doutorando resume bem a situação: 
Acho que no final do doutorado... [interrompe a frase e explica:] Porque se você quer ficar aqui [no departamento] você tem que ter muitos artigos... [retomando:] Então você começa a entrar num ritmo meio frenético... Mas eu acho que o final do doutorado é assim mesmo, você tem que meter a cara, tem que trabalhar muito, tem que trabalhar fim de semana se precisar... Porque é quando você vai estar terminando e é tudo que você vai ter para conseguir emprego... Então eu acho que você vai ter que dar o melhor de si mesmo!

Essa era a atitude geral. Todos sabiam dessas regras. Talvez, por causa disso, não tenham sido observadas diferenças importantes entre os relatos femininos e os masculinos no que tange às expectativas de futuro na carreira. Sabia-se que a inserção institucional depois do doutorado seria tarefa árdua e apenas 'os melhores seriam eleitos'. Diante disso, e sem caminhos clara e previamente planejados para a carreira em ciências, as possibilidades vislumbradas pelos doutorandos para o futuro foram as seguintes:

- fazer pós-doutorado (dando continuidade ao processo de formação, sem vínculo empregatício, relação temporária com a instituição);

- atuar como professor visitante (no departamento de origem ou em outro, com vínculo empregatício formal, mas temporário, com a instituição de ensino);

- participar de algum projeto em colaboração com outra instituição ou departamento (vínculo de assistente de pesquisa ou pesquisador, com duração compatível com a duração do projeto de pesquisa);

- fazer concurso para uma universidade pública (vínculo empregatício formal e tempo indeterminado);

- trabalhar em instituição privada de ensino (vínculo empregatício formal e de tempo indeterminado).

Apenas em um dos relatos foi possível encontrar uma definição clara a respeito do futuro. A opção era continuar a formação num pós-doutorado no exterior:

- Eu quero fazer postdoc... Mas não sei ainda em quê, mas a idéia é essa... A princípio, foi o que o $\mathrm{X}$ [orientador] me sugeriu...

- E o que você acha?

- Eu concordo com ele.

Aqui temos uma marca desses doutorandos: mesmo sem a certeza do que fazer no futuro (projeto ou inserção institucional), seguem firmes na posição de que devem 'continuar na pesquisa'. Isto também pode ser visto neste outro relato: 
- Na verdade está surgindo uma oportunidade, nem sei se vai para frente... Porque eu só vou contar mesmo quando estiver certo... é fora do Rio, também foi uma indicação do Z [orientador], uma pessoa que ele conhece lá em Campinas. Tenho uma outra possibilidade...

- E o que você faria lá?

- Na verdade não sei! [risos] Porque eles trabalham lá com uma coisa completamente diferente do que eu trabalho, eles trabalham com biologia molecular de planta... [risos]

A saída do laboratório aparece nos relatos como um momento muito especial. Sair significa 'andar com as próprias pernas'. A importância desse momento talvez possa ser associada ao longo tempo de permanência desses estudantes com um mesmo orientador, no mesmo laboratório, não sendo raro que a entrada na atividade de pesquisa tenha se dado no início da graduação (iniciação científica).

A incerteza que envolve o momento leva esta outra doutoranda a ressaltar a flexibilidade necessária no término do curso. Além disso, aparece aqui uma revelação importante a respeito de sua atividade:

Eu vou para onde a onda me levar. Se tiver que fazer um postdoc eu vou fazer, porque aí é a continuação da minha formação. Porque depois do postdoc eu vou ter que fazer um concurso e tudo isso conta no teu currículo. Isso para um objetivo maior na frente, mas eu não descarto a possibilidade de sair da universidade ou fazer outros trabalhos paralelos... [Porque] o único mercado que a gente conhece é o acadêmico, que teoricamente quando a gente entra nessa linha é para seguir a área acadêmica mesmo. Eu não tenho coisa para fazer, eu vou dar aula ou vou seguir a carreira acadêmica, entendeu? ... Então eu não sei até que ponto a pós-graduação na minha área, ela tem mercado, porque não existe um mercado, entendeu? Então a pós-graduação, para mim, é um emprego. Eu falo para as pessoas: "eu vou para o trabalho, eu vou para o trabalho". Meu trabalho é isso aqui ... A minha profissão é mestranda, doutoranda, recém-doutora, até chegar numa profissão efetiva, em que vou ter um contrato assinado, em que vou ter carteira assinada, essas coisas...

Aqui o doutorado aparece como 'trabalho', e mais, como 'profissão' . Pelo menos, existem dois aspectos a destacar. O primeiro: a referência ao trabalho durante a formação envolve uma característica da formação de pesquisadores que é a relação estreita com um pesquisador estabelecido e a exigência de domínio sobre uma atividade que não se encontra totalmente codificada. Nem tudo o que se faz na pesquisa se encontra nos livros e nos papers. Aprender a pesquisar remete a uma aquisição de conhecimento cotidiano, táci- 
to, que vai se dando paulatinamente, no contato direto 'com quem sabe fazer'.

Discutindo o ofício do intelectual, Bourdieu (2001) lembra Polanyi e afirma que os pesquisadores, em geral, têm dificuldades para definir sua atividade, assim como os artistas e os esportistas. Segundo ele, os pesquisadores, quando falam informalmente de sua pesquisa

ils la décrivent comme une pratique, du flair, du 'pifomètre', autant de choses que sont difficiles à transcrire sur le papier et qui ne peuvent être comprises et acquises vraiment que par exemple et à travers un contact personnel avec des personnes competentes. (p. 80)

Outro aspecto a destacar no relato citado anteriormente: ele pode remeter a um determinado uso desse trabalho durante o treinamento em ciências. Dado o aumento da competitividade no campo durante os últimos anos (De Meis et al., 2003; Louzada \& SilvaFilho, 2003), essa forma de treinamento pode dar lugar a uma distorção nem sempre explicitada. No relato a seguir, de uma outra doutoranda, a questão parece ficar mais clara:

eu passei o primeiro ano do doutorado... Eu não fiz nada praticamente, não fiz, foi realmente um ano perdido no doutorado ... [Muitas] atividades burocráticas que a gente leva nas costas muito. Lato sensu, curso de férias, relatório disso, projeto daquilo, então... isso atrapalha bastante, não é?

É evidente aqui a participação dessa doutoranda em atividades - chamadas 'burocráticas' - alheias ao seu projeto de pesquisa. Vários entrevistados fizeram referências, ainda que indiretas, a tarefas desse tipo. É um dado relevante quando se pensa as expectativas de carreira na medida em que o doutorando também é avaliado, ainda que informalmente, por sua capacidade de desenvolver as tarefas cotidianas do laboratório (ensino, pesquisa, compras e segurança, entre outras). Esta é uma questão importante e merece ser enfrentada em nosso meio, já que, no exterior, o debate que tem sido travado quanto ao tema busca clarificar cada vez mais o estatuto dos pós-graduandos e postdocs em função da complexificação do campo científico. ${ }^{8}$ No âmbito nacional, recentemente, o futuro dos recém-doutores também tem sido discutido. ${ }^{9}$ Ambos os debates partem de um mesmo evento: o aumento do contingente de pesquisadores habilitados.

De maneira geral, os entrevistados desta pesquisa almejam um contrato de trabalho por tempo indeterminado, seu objetivo principal é o 'concurso' para uma universidade pública. Apenas uma doutoranda manifestou desejo de trabalhar em uma instituição de ensino privada. E nenhum deles fez referência a um possível traba- 
lho em outro tipo de empresa. Essa parece uma tendência nos pósgraduandos brasileiros, já que alguns estudos quantitativos trazem dados que caminham nessa direção. Braga e Azevedo (2002), embora trabalhando com titulados e não com pós-graduandos, encontraram $86,6 \%$ de inserção na academia e apenas 3,2\% no mercado, na área de química. Na mesma linha, Bôas, Barbosa e Maggie (2002), estudando nove áreas de conhecimento (administração, agronomia, bioquímica, clínica médica, engenharia civil, engenharia elétrica, física, química e sociologia), encontraram altos índices de doutores inseridos na academia, sendo os doutores em sociologia os de menor inserção (cerca de 58\%). Todas as outras áreas apresentaram percentual alto, com destaque para a de química, com $85,9 \%$. Dessa lógica não se desviam nem as engenharias, também com alto percentual de doutores na academia (civil com 74,3\%, e elétrica com $84,7 \%)$.

Tais dados, obtidos em nosso meio, se distinguem de maneira importante dos achados de Mangematin (2000). O autor, ouvindo pós-graduandos em engenharia, no âmbito da França encontrou uma distribuição diferente de respostas quanto aos planos para o futuro, no mundo da pesquisa. Em suas palavras:

When asked what their professional plans are, only $37,5 \%$ say that they invest in a PhD in order to enter academia. Almost one-third of them plan to apply for a job in private sector research. (p. 751)

A distinção talvez possa ser remetida aos diversos modos de formação dos doutores (Brasil versus França), mas também aos níveis nacionais de desenvolvimento e de políticas públicas (C\&T, industrial e seguridade, entre outras).

Em nossa pesquisa, o que salta aos olhos é a indefinição quanto ao futuro. Antevendo as possíveis dificuldades de inserção, os doutorandos apontaram como alternativa ao emprego efetivo (concurso para universidade pública ou emprego em instituição privada), algo que os 'mantivesse fazendo pesquisa'. As vias possíveis: a 'colaboração', um 'pós-doutorado' ou um 'contrato de professor visitante'. ${ }^{10}$ Vejamos como aparecem essas duas alternativas nas falas dos estudantes:

- Por enquanto penso só em terminar. Mas ainda tem que ver... talvez mandar projeto para a Faperj, para ver se tem retorno, não sei se vai conseguir, de professor visitante... A gente também está fazendo colaboração com a instituição $X$... Então, tem essa colaboração, que talvez consiga uma bolsa [sic] de professor visitante ... é um projeto que visa tentar dar uma melhorada na pós-graduação [de lá], que foi fechada porque recebeu menos de dois no conceito... Então o que a pós-graduação daqui está tentando, é colocar gente lá... Enfim, então a gente, as pessoas daqui 
vão ajudar lá, enquanto isso há um espaço que a gente pode ter a mais para se fixar depois...

- E o que você pensa com relação ao seu futuro?

- Ah... Eu quero ficar na universidade... Ele [orientador] tentaria uma bolsa [sic] de professor visitante para mim. Mas eu ainda estou em dúvida, não sei se é isso que eu quero. Não sei mesmo. Eu gostaria de ter agora uma oportunidade de eu dar aula numa universidade particular... mas não é assim... Não adianta eu querer, não é? [risos] Tem que ser chamada. Já mandei currículo para algumas, preciso mandar para outras... Eu não tenho vontade de fazer concurso para cá ... Tanta loucura isso aqui...

Agora... Eu estou sem perspectiva... Estou como professor substituto da universidade $\mathrm{X}$, meu contrato está terminando, em maio do ano que vem, e não tem concurso... Parece que tem duas possibilidades que a gente está tentando acionar: a primeira é fazer o postdoc na instituição $X$, porque eu tenho uma colaboração com o professor Y e a professora Z. É uma coisa que eu procurei, falei com ela... também está bem adiantada, a gente já vai escrever um projeto lá dentro da instituição $X$ para tentar conseguir um dinheiro lá por dentro, em cima desse trabalho...

No primeiro relato é possível ver o contrato de 'professor visitante' e a 'colaboração' como forma de 'colocar gente lá', ou seja, de inserir o aluno institucionalmente, ainda que de forma precária, por tempo determinado. No segundo relato percebe-se o contrato de professor visitante - chamado de 'bolsa' - como um 'convite' do orientador. A doutoranda mesmo não se encontrava muito envolvida; sonhava, na verdade, com um trabalho numa universidade privada. Já no terceiro relato a colaboração é citada como uma possibilidade para uma situação atual 'sem perspectiva'. Ou seja, surgem nos relatos três níveis de relações que podem abrir a possibilidade do contrato: pela política institucional, pelas relações pessoais entre os docentes/pesquisadores (colaborações) e pela via individual, que parece representar um caminho mais tortuoso. De toda maneira, é importante sublinhar que, mesmo sem perspectivas muito claras quanto ao futuro, esses pós-graduandos vão compondo/investindo (em) uma rede de relações (institucionais, profissionais e pessoais) que talvez possibilite algum tipo de inserção ou financiamento futuro.

A importância dessas relações também aparece no trabalho de Mangematin \& Robin (2002) - um survey com 652 pósgraduandos (ciências da vida). Encontramos na pesquisa a seguinte afirmação: "Close to 50\% of PhD graduates say that they found their first job through contacts made during their doctoral training. Thus, a PhD student's professional environment strongly influences herl his future career" (p. 120). 
Dito de outra maneira, o sucesso na futura carreira científica envolve inúmeros fatores. Tal posição afina-se, em grande parte, com o que nos diz Bourdieu (1982) quando estuda o aspecto arbitrário das seleções, dos concursos etc. Para esse autor os ritos escolares e acadêmicos instituem algo, através deles se reconhece (ou não) uma determinada performance ou prática. Importa, portanto, lançar luz sobre os critérios utilizados nos rituais acadêmicos, a linha que divide os aprovados e os reprovados. Dentro dessa visão, encontra-se totalmente relativizada a idéia de que há características inerentes aos sujeitos, no que se refere aos talentos, vocações etc.

Dentro dessa visão, o futuro pesquisador, para conseguir êxito, deverá conhecer as regras da academia (ou seja, a linha que divide os de dentro e os de fora, os bem-sucedidos dos demais), assimilando-as; deverá, enfim, submeter-se a um 'processo de ordenação' ou 'consagração' ${ }^{11}$ Este processo é descrito como permanente, concretizando-se através da assimilação de pequenos hábitos e comportamentos, característicos de uma determinada comunidade escolar.

Para os entrevistados, uma regra nesse ambiente era clara: a necessidade da publicação em 'boas revistas'. Todos sabiam que as publicações faziam a diferença. Mas, além disso, os relatos indicaram uma outra regra: a necessidade de trabalhar mais. Nas palavras de um doutorando:

como eu acho que o departamento não quer deixar a bola cair, fica uma pressão muito grande. [pausa] E uma coisa engraçada, porque não é uma coisa explícita, ninguém chega para você e diz: "olha você tem que trabalhar mais, você tem que produzir mais...". Mas todo mundo sabe que você tem! Então é uma coisa meio por baixo dos panos...

Aqui, uma afinidade com os achados de Mangematin (2000). Os pós-graduandos em engenharia, estudados pelo autor no âmbito da França, também sabiam da necessidade de publicações para permanecer no meio acadêmico: "Those who plan to get a job in academia publish more than those who plan to join the private sector" (p. 752).

Vale também ressaltar que nosso grupo de doutorandos se encontrava num campo de conhecimento em que o 'processo de ordenação' inclui o estabelecimento de muitas trocas científicas, com grande fluxo de idéias e recursos (humanos ou não) em nível nacional e internacional. Pode-se dizer, com base nas afirmações anteriores, que a rede de relações entre pesquisadores e instituições é conseqüência e causa de outras (que redundam em auxílios, contratos etc.), caracterizando a permanência do processo - considerado aqui para além do nível individual, já que é possível perceber uma acumulação de capital cultural para o próprio grupo de pesquisadores. Ou seja: o 'capital/poder' acumulado autoriza uma prática que se funda nas 
relações e as produz, num vai-e-vem contínuo. Tal movimento parece ampliar a experiência e o conhecimento dos pós-graduandos, orientadores e chefes de laboratório a respeito não só do seu próprio campo de conhecimento como das regras do jogo no mundo da ciência e suas mutações.

Sobre essas mutações, destacamos o relato de uma doutoranda que faz uma reflexão sobre as futuras vicissitudes de tornar-se uma 'pesquisadora independente'. Aqui vale abrir parênteses para indicar que, nos relatos de todos os sujeitos, esse é o lugar mais desejado. Para se tornar um pesquisador independente, eles sabem, vão precisar não apenas do título de doutor, mas também terão de obter financiamento, orientar aluno de pós-graduação, ter seu próprio laboratório e publicar sem a ajuda do orientador. ${ }^{12}$ E é falando sobre o último item (publicação) que uma doutoranda estranha - e brinca com - algumas regras acadêmicas e práticas a elas relacionadas:

aí agora é assim [fazendo falsete e enfática]: “Fulano tem vinte artigos". [retomando o tom] "Mas pô, vinte artigos assim, três no Brazilian Journal..." "Ah, não! Fulano tem cinco, mas cinco na Nature..." Agora é grau de impacto, entendeu? [rindo] É troço de maluco! Agora não só se analisa o número de papers, mas as revistas! Qual é o impacto? E aí a imprensa lança a... lista de Schindler, já ouviu falar da 'lista de Schindler'? [risos] O ranking dos pesquisadores... Aí fica lá: “O X também, o cara põe o nome dele em tudo, é só usar o microscópio dele, pô!” [risos] É só isso que você escuta! O cara nem sabe quem [inaudível] mas se o estagiário foi lá, usou o microscópio eletrônico, ele botou o nome dele. É assim! as pessoas ficam o tempo inteiro te julgando pela produtividade, por onde você produz, de que maneira...

A produtividade, medida através das publicações, passa a ser critério para financiamentos, e não apenas nesta área. De Meis et al. (2003) chegaram a considerar o momento da publicação como o principal 'rito de passagem' no meio científico brasileiro.

Para os entrevistados a publicação é reconhecida como uma atividade-chave na ciência, mas parece haver outros degraus a subir. Para esses estudantes de pós-graduação, a publicação deve, ainda que no futuro, ser articulada ao título de doutor. Além disso, restariam, pela ordem, obter financiamento, ter alunos de pós-graduação, e ter seu próprio laboratório. Esses parecem ser os passos valorizados para se chegar ao lugar de pesquisador independente. A publicação, sempre. Mas todos os outros itens, gradativamente, devem ser incluídos na construção da carreira em ciências.

No momento em que estavam, os pós-graduandos sabiam que para obter financiamentos futuros deviam publicar e elaborar projetos que 'vendessem bem', como nos diz este outro entrevistado: 
Eu vou passar, daqui a pouco tempo, em seis meses eu sou doutor, menos de seis meses agora... E aí você vive mais ou menos uma situação em que você deixa de ser o futuro do Brasil e passa a ser um problema social, porque você está desempregado... Porque antigamente o doutorado... o doutorado vai ser sempre tomado como o futuro do Brasil, mas você fica desempregado no final, quer dizer, eu vou procurar emprego em algum lugar, mas sempre passa pela idéia de que você vai precisar montar um laboratório seu, procurar dinheiro, e você começa a trabalhar com questões as quais você pensa que vendam bem, que tragam dinheiro. E é isso que eu vou começar a fazer, vou escrever projetos que envolvam essa historinha que eu te contei...

É possível ver aqui mais claramente a existência de um 'mercado de capitais simbólicos' (projetos que circulam) pelo qual se acessa o capital econômico (procurar dinheiro), base para a atividade de pesquisa.

Esse último relato revela também uma outra questão que nos parece central: na incerteza quanto à futura inserção laboral, os futuros pesquisadores articulam-se, com as ferramentas que possuem, para se manter no mundo da pesquisa. E isto pode envolver deixar de lado um projeto para obtenção de financiamento em área afim. Esse procedimento, referido como rotineiro no meio, talvez seja o modo de se manter no jogo e desenvolver os projetos que realmente interessam.

\section{Considerações finais}

Embora este trabalho apresente limitações quanto ao processo de generalização, é possível considerar que, estando os sujeitos inseridos em um programa de pós-graduação de excelência, suas experiências e relatos possam funcionar como indicadores do impacto de uma determinada organização da pesquisa científica - apoiada na produtividade e com importantes restrições orçamentárias sobre as futuras trajetórias laborais.

Ficou evidente, a partir do material coletado, que 'estar formado', expressão várias vezes referida pelos sujeitos, significava ter o título de doutor. No entanto, e paradoxalmente, podemos dizer que o título de doutor não aparece como um signo de distinção privilegiado. Ser doutor significa, para o grupo, apenas estar habilitado a iniciar um caminho de 'pesquisador independente', lugar de maior distinção. Para se tornar um pesquisador independente os doutorandos devem ainda possuir mais alguns requisitos, que figuram como outros signos de distinção. E para chegar a ser pesquisador independente os entrevistados trabalhavam muito para, pelo menos, terminar o doutorado com publicações relevantes, em periódicos de destaque. Isto os habilitaria a começar uma trajetória 
acadêmica. Uma estudante resumiu a situação numa frase: “a moeda nesta arena aqui é a publicação".

Foi possível ver também, nos relatos, a preocupação dos pósgraduandos com o futuro emprego. Isto de maneira alguma é característica exclusiva desse grupo, pois se acompanha, no país, a discussão relevante a respeito da futura inserção de doutores, haja vista o grande número de habilitados para a pesquisa e os poucos postos de trabalho. ${ }^{13}$ Essa preocupação vem sendo compartilhada pelos órgãos brasileiros de fomento que respondem, ainda que de maneira tímida, com programas específicos.

A maior parte dos sujeitos pretendia atuar na universidade (pública) e as alternativas ao emprego fixo apontadas eram dependentes de instituições de fomento (pós-doutorado, projetos de pesquisa em colaboração) ou atividade temporária (professor visitante). Tal tendência também foi observada em outros países (Estados Unidos e Reino Unido, por exemplo), onde os doutores têm levado mais tempo para conseguir uma posição estável.

Com os dados encontrados e com suporte da literatura pode-se pensar na hipótese, a ser explorada em novas pesquisas, de que o trabalho em ciências mostre indícios de precarização, com alongamento da formação (postdoc), contratos temporários (professor visitante) e indefinição de estatutos (colaboração). Os resultados se afinam, em suma, com dados internacionais que indicam uma tendência dos doutores em recorrer cada vez mais a posições protegidas.

Pode-se, enfim, dizer com Bourdieu que o treinamento em pesquisa, realizado no laboratório, não pode ser entendido sem que se considere o campo científico - e a sociedade - em seu movimento.

\section{NOTAS}

${ }^{1} \mathrm{Cf}$. Trends in the early careers of life scientists. Committee on Dimensions, causes, and implications of recent trends in careers of life scientists, 1998.

2 Cf. Science $\mathcal{E}$ engineering indicators, 2000.

${ }^{3}$ Cf. Enhancing the postdoctoral experience for scientists and engineers: a guide for postdoctoral scholars, advisers, institutions, funding organizations and disciplinary societies, 2000.

${ }^{4}$ Cf. Allen-Collinson \& Hockey, 1998.

${ }^{5}$ Cf. discurso proferido pelo presidente da República em 3.4.2000 (Jornal da Ciência, 14.4.2000) e Loureiro, 1998.

${ }^{6}$ O lançamento da nova proposta quanto ao sistema de financiamento da pesquisa científica e tecnológica brasileira foi feito em 3.4.2000 pelo presidente da República (Jornal da Ciência, 14.4.2000). Vários fundos já se encontram em funcionamento.

${ }^{7}$ Ao enfocar a formação de pesquisadores brasileiros, vale lembrar que esta nem sempre esteve ligada à pósgraduação. Tal fenômeno passa a ocorrer a partir da década de 1960. Segundo Beiguelman (1998), antes disso os estudos pós-graduados eram raros no país e, portanto, o número de doutores muito reduzido. A partir de 1965 a situação começa a mudar com a regulamentação da pós-graduação (Azevedo, 31.1.2002). 
${ }^{8} \mathrm{Cf}$. Enhancing the postdoctoral experience for scientists and engineers: a guide for postdoctoral scholars, advisers, institutions, funding organizations and disciplinary societies, 2000, e Graduate Education in the chemical sciences: issues for the $21^{\text {st }}$ century: report of a Workshop Chemical Sciences Roundtable, Board on Chemical Sciences and Technology, National Research Council, 2000.

${ }^{9}$ Recentemente a SBPC promoveu um debate a respeito do tema com autoridades governamentais, professores e recém-doutores no CBPF, Rio de Janeiro, com resumo publicado em 7.11.2003, no JC E-mail.

10 " $L$ ' opération de division qui distingue, dans le continuum des performances ... deux populations séparées, et pour la vie, est une acte de consécration ou, si l'on préfère, d'ordination qui ... institue un ordre, c'est-à-dire, une division légitime, magiquement produite et juridiquement garantie, du monde social..." (Bourdieu, 1989, p. 141).

11 Quanto às colaborações, sabe-se que são comuns entre instituições científicas e cada vez mais recomendadas. Os pesquisadores estabelecem regras para as trocas de recursos (humanos, financeiros etc.) e trabalham em parceria. As trocas inter-institucionais são cada vez mais valorizadas por instituições de fomento e funcionam como sinal de regularidade na troca de informações, e, por extensão, de qualidade na produção científica. Já o contrato de professor visitante se caracteriza como emprego efetivo, ainda que temporário. Através dele o pesquisador incorpora-se ao staff, inserindo-se nas atividades departamentais de ensino e pesquisa.

12 Este parece ser o capital que permite ser considerado 'verdadeiro cientista', expressão usada por Carmo (2001). Os adjetivos colhidos pela autora, em sua pesquisa de campo (por exemplo a categoria 'gênio'), podem estar relacionados com a consecução desses itens, e, somente em função deles, pode-se falar nessas características dos sujeitos. Dito de outra maneira, o que normalmente aparece como talento individual, vocação, ancorase, a nosso juízo, em condições sociais muito concretas, como, por exemplo, a efetiva publicação de um artigo, a disponibilidade financeira, a obtenção de prêmios etc. Pode-se dizer, enfim, que o talento, a vocação científica se produz e expressa a partir de condições sociais bem determinadas.

13 A carência de postos de trabalho na pesquisa no Brasil terminou ganhando visibilidade internacional com o surgimento do chamado 'movimento de jovens doutores brasileiros', com repercussão a partir da publicação do manifesto na revista Nature e divulgação de um site na internet. Cf. www.geocities.com/jadauto.geo/manifesto e Ribeiro, 2001.

\section{REFERÊNCIAS BIBLIOGRÁFICAS}

Allen-Collinson, J.; Hockey, J. 1998

Azevedo, J. C. 31.1.2002

Bardin, L. 1987

Balbachevsky, E. 2000

Beiguelman, B. 1998

Bôas, G. V.; Barbosa, M. L.; Maggie, I. 2002

Bourdieu, P. 1997

Bourdieu, P. 1989

Bourdieu, P. juin 1984
Capturing contracts: informal activity among contract researchers. British Journal of Sociology of Education, v. 19, n. 4, p. 497-513.

Fatos e circunstâncias. JBonline. Disponível em: jbonline.terra.com.br/papel/opiniao/2002/01/30/joropi20020130003.html

Análise de conteúdo. Lisboa: Ed. 70.

A profissão acadêmica no Brasil: as múltiplas facetas do nosso ensino superior. Brasília: Funadesp.

Reflexões sobre a pós-graduação brasileira. In: Palatnik, Marcos et al. (org.) A pós-graduação no Brasil. Rio de Janeiro: UFRJ.

A pós-graduação, a academia e as trajetórias profissionais. In: Velloso, J. (org.) A Pós-graduação no Brasil: formação e trabalho e mestres e doutores no país. Brasília: Capes.

Les usages sociaux de la science: pour une sociologie clinique du champ scientifique. Paris: INRA.

La noblesse d'Etat. Grandes ecoles et esprit de corps.

Paris: Minuit.

Espace social et génèse des 'classes'.

Actes de la Recherche en Sciences Sociales, n. 52-53, p. 3-12. 
Bourdieu, P.

juin 1982

Bourdieu, P. 2001

Braga, M. M.;

Azevedo, S. 2002

Carmo, M. S. 2001

De Meis, L.; Leta, J. 1998

De Meis, L.; Leta, J. 1996

De Meis, L.; Velloso, A.; Lannes, D.; Carmo, M. S.; De Meis, C. 2003

Dourado, L. F.; Catani, A. M. 1999

Easthope, C.; Easthope, G. 2000

International Workshop training and career 2002

Langenberg, $\mathrm{H}$. 2001

Leta, J. 1999

Leta, J.; Lannes, D.; De Meis, L. 1998

Loureiro, L. V. 1998

Louzada, R. C.;

Silva-Filho, J. F.

Dec. 2003

Mangematin, $\mathrm{V}$. 2000

Mangematin, V.; Robin, $\mathrm{S}$.

2002
Les rites comme actes d'institution.

Actes de la Recherche en Sciences Sociales, n. 43, p. 58-63.

Science de la science et reflexivité.

Paris: Raison d'agir.

Mestres e doutores em química. In: Velloso, J. (org.) A pós-graduação no Brasil: formação e trabalho e mestres e doutores no país.Brasília: Capes.

O cientista em formação: o quotidiano de uma pós-graduação de excelência (nível 7 Capes). Rio de Janeiro, Departamento de Bioquímica Médica/UFRJ. Dissertação de Mestrado.

Ciência e educação: o conflito humano-tecnológico.

Rio de Janeiro: Ed. do autor.

O perfil da ciência brasileira.

Rio de Janeiro: Ed. UFRJ.

The growing competition in Brazilian science: rites of passage, stress and burnout. Braz J Med Biol Res, v. 36, n. 9, p. 1135-41 (Concepts andComments).

Universidade pública: políticas e identidade institucional.

Campinas (SP): Autores Associados, Goiânia: Ed. UFG.

Intensification, extension and complexity of teachers' workload.

British Journal of Sociology of Education, v. 21, n. 1.

Changing modes of knowledge production and labor markets.

Netherlands: University of Twente.

Uncertainty of short-term contracts is turning talent away from science. Nature, v. 410, p. 849-50.

A pós-graduação e a formação de recursos humanos para ciência e tecnologia no Brasil. Rio de Janeiro, Departamento de Bioquímica Médica/UFRJ (tese de Doutoramento).

A formação de recursos humanos e a produção científica no Brasil In: Palatnik, Marcos et al. (org.) A pós-graduação no Brasil. Rio de Janeiro: UFRJ.

A distribuição regional da pós-graduação no país e a atuação da Capes. In: Palatnik, Marcos et al. (org.) A pós-graduação no Brasil. Rio de Janeiro, UFRJ.

Competitiveness is pushing scientists to the edge. SciDev. Science and Development Network. Letter. Disponível em: www.scidev.netEditorLetters

PhD job market: professional trajectories and incentives during the PhD. Research Policy, 29, p. 741-56.

The Double face of PhD students. The Example of Life Sciences. International Workshop Science, training and career. Changing modes of knowledge production and labor markets. Netherlands: University of Twente.

Enhancing the Postdoctoral Experience for Scientists and Engineers: A guide for postdoctoral scholars, advisers, institutions, funding organizations, and disciplinary societies. Washington (DC): National Academies Press. 
NRC

2000

NRC

1998

NSF

Peixoto, M. C. L. 1994

Reis, G. A. 1998

Ribeiro, S. P.

5.10.2001

Scheinberg, G.

12.3.2000

Schwartzman, S. 1979

Slaughter, S.; Leslie, L. 1997

Spagnolo, F.;

Gunther, $\mathrm{H}$. 1986

Velloso, J. (org.) 2002
Graduate Education in the Chemical Sciences: Issues for the 21st Century: Report of a Workshop Chemical Sciences Roundtable. Washington (DC): Board on Chemical Sciences and Technology, National Research Council.

Trends in the Early Careers of Life Scientists. Committee on Dimensions, Causes, and Implications of Recent Trends in Careers of Life Scientists. Washington (DC): National Research Council.

Science and Engineering Indicators-2000. Arlington, Washington (DC): National Science Foundation/Division of Science Resources Statistics.

Escola de pesquisar: estudo sobre a formação do pesquisador. Rio de Janeiro: Faculdade de Educação/UFRJ (tese de Doutoramento).

A qualidade da formação de doutores e o financiamento a grupos de pesquisa no Brasil: as relações óbvias e as nem tanto. In: Palatnik, Marcos et al. (org.) A pós-graduação no Brasil. Rio de Janeiro: Ed. UFRJ.

Jovens doutores recebem apoio após publicação do Manifesto na Nature. Comciencia. Disponível em: www.comciencia.br/noticias

Cresce a pesquisa no Brasil. Folha de S. Paulo. Disponível em: www1.folha.uol.com.br/fsp/ciencia/fe1203200003.htm

Formação da comunidade científica no Brasil.

São Paulo: Ed. Nacional.

Academic capitalism. Politics, policies and the entrepreneurial university.

Baltimore, London: Johns Hopkins University Press.

Vinte anos de pós-graduação: o que fazem nossos mestres e doutores? Ciência e Cultura, v. 38, n. 10, p. 1643-62.

A Pós-graduação no Brasil: formação e trabalho e mestres e doutores no país, v. 1. Brasília, Capes. 